\title{
Targeted Radionuclide Therapy for Neuroendocrine Tumours: Principles and Application
}

\author{
Maralyn R. Druce $^{a} \quad$ Val Lewington ${ }^{b}$ Ashley B. Grossman ${ }^{a}$ \\ ${ }^{a}$ Centre for Endocrinology, Barts and the London School of Medicine, and ${ }^{b}$ Department of Nuclear Medicine, \\ Royal Marsden Hospital, London, UK
}

\section{Key Words}

Neuroendocrine tumours · Carcinoid •

Gastroenteropancreatic neuroendocrine tumours •

Phaeochromocytoma - Radionuclide

\begin{abstract}
Neuroendocrine tumours comprise a group of neoplasms with variable clinical behaviour. Their growth and spread is often very slow and initially asymptomatic, and thus they are often metastatic at the time of diagnosis and incurable by surgery. An exciting therapeutic strategy for cytoreduction, both for stabilisation of tumour growth and inhibition of hormone production, is the use of targeted radionuclide therapy. Evidence from large-scale, randomised, placebocontrolled trials is very difficult to obtain in these rare diseases, but current data appear promising. It is timely to review the principles underlying the use of these therapies, together with the clinical outcomes to date and potential directions for future research.
\end{abstract}

Copyright $\odot 2009$ S. Karger AG, Basel

\section{Introduction}

Neuroendocrine tumours comprise a heterogeneous group of neoplasms which originate from endocrine cells, both within endocrine organs and within the cells of the diffuse endocrine system. The clinical behaviour of such tumours is variable; they range from well-differentiated, slow-growing tumours to poorly differentiated, highly invasive malignancies and may be functioning or nonfunctioning [1]. While surgery is currently the only available curative treatment, at the time of diagnosis many are non-resectable. Other treatment options aim to control the symptoms caused by the production of hormone products and/or achieve cytoreduction with stasis or shrinkage of tumour bulk.

Radionuclides are unstable forms of chemical elements which undergo radioactive decay, resulting in the emission of nuclear radiation. This radiation interacts with human tissue causing DNA damage and cell death. In addition to direct nuclear damage, adjacent cells may also be damaged. This may be via spread of radiation energy beyond the target cell or due to the release of toxic metabolites from damaged cells to those in the vicinity [2]. This so-called 'bystander effect' is complex and may involve the release of free radicals or toxins, causing local inflammation and vasculitis [3].

Delivery of ionising radiation from outside the body (external beam radiotherapy) requires photon energies of several million electrovolts to penetrate tissues and reach deep-seated tumours. The radiation dose absorbed by the tumour is constrained by dose-limiting toxicity to nontarget tissues, although improvements in planning methods such as conformal radiation techniques and intensi-

\section{KARGER \\ Fax +4161306 1234 \\ E-Mail karger@karger.ch}

www.karger.com
(C) 2009 S. Karger AG, Basel

0028-3835/10/0911-0001\$26.00/0

Accessible online at:

www.karger.com/nen
A.B. Grossman

Department of Endocrinology, St Bartholomew's Hospital

West Smithfield

London EC1A 7BE (UK)

Tel. +44 207601 8343, Fax +44 207601 8505, E-Mail a.b.grossman@qmul.ac.uk 
ty-modulated radiotherapy have been introduced to mitigate this effect. Radiopharmaceutical therapies employ a nuclide within the body directed towards a specific target. Targeting may be direct, such as physiological ${ }^{131} \mathrm{I}$ uptake facilitated by the biology of thyroid tissue, or may involve the coupling of a radionuclide to a molecule which carries the radioactive atom to its target tissue [4], which receives a high dose of radiation energy while minimising potential toxicity to nearby healthy tissue [5]. This also enables treatment of small lesions including subclinical deposits too small to be imaged or managed by surgery or external beam radiotherapy [6].

Treatment success depends on several parameters, including features of the radionuclide, characteristics of the radiopharmaceutical, the nature of the disease process and patient features.

\section{Features of the Radionuclide}

\section{Emission Types}

The nuclear composition of radionuclides is unstable, returning to the ground state via one or more nuclear decay events. Alpha decay is the emission of a particle equivalent to the nucleus of a helium atom, with high energy but short path length. Beta radiation consists of a light, short-range particle in the form of an ejected electron. Gamma radiation comprises high-energy electromagnetic waves with long path lengths and thus very high tissue penetration [7]. Auger electrons are produced when an electron is ejected from the atom as beta radiation and an electron from a higher energy shell falls into the resultant vacancy. This fall results in the transfer of energy which may either be expressed as a photon, or transferred to another peripheral electron and then expelled (the Auger electron) [8]. Auger emitters carry high energy but only over a very short distance, so are only effective if the treatment complex is internalised within the cell, preferably close to or within the nucleus. Conversion electrons are produced by in a metastable nucleus by energy transfer to an electron which subsequently becomes free. The types of emission are summarised in table 1 , and a given radionuclide may produce one or more of these.

\section{Particle Energy}

Radionuclides are cytotoxic as the energy they transmit causes ionisation, leading to cell disruption, damage and death. The different types of radiation confer differing amounts of energy, usually expressed as Becquerels (Bq, disintegrations per second) [7].
Table 1. Examples of different types of radioactive emissions

\begin{tabular}{|c|c|}
\hline Mode of decay & Particle/emitter \\
\hline \multicolumn{2}{|c|}{ Decays with emission of nucleons } \\
\hline Alpha decay & alpha particle (He nucleus) \\
\hline Proton emission & proton ejected from nucleus \\
\hline Neutron emission & neutron ejected from nucleus \\
\hline Spontaneous fission & $\begin{array}{l}\text { nucleus disintegrates into two or more } \\
\text { smaller nuclei and other particles }\end{array}$ \\
\hline Cluster decay & $\begin{array}{l}\text { nucleus emits a specific type of small- } \\
\text { er nucleus }\end{array}$ \\
\hline
\end{tabular}

Different modes of beta decay

Beta negative decay nucleus emits an electron and antineutrino

Beta positive decay nucleus emits positron and neutrino (positron emission)

Electron capture

nucleus captures an orbiting electron and emits a neutrino

Electron capture with positron emission

Auger emission nucleus absorbs one orbital electron, emits one positron and two neutrinos electron ejected from core level, higher level electron falls in to fill space, excess energy lost in second ejected electron

Transition between different states of nucleus

Gamma decay

excited nucleus releases a high-energy photon (gamma ray)

Internal conversion excited nucleus transfers energy to an orbital electron and it is ejected from the atom

Table 2. Physical properties of some isotopes in use for targeted radiotherapy

\begin{tabular}{llcll}
\hline $\begin{array}{l}\text { Radio- } \\
\text { isotope }\end{array}$ & Emission & $\begin{array}{l}\text { Half-life } \\
\text { days }\end{array}$ & $\begin{array}{l}\text { Max. range } \\
\mathrm{mm}\end{array}$ & $\begin{array}{l}\text { Energy } \\
\mathrm{keV}\end{array}$ \\
\hline${ }^{153} \mathrm{Sm}$ & beta, gamma & 1.9 & 3.1 & $\begin{array}{l}233 \text { (vari- } \\
\text { able, range } \\
\end{array}$ \\
& & & & $103-810)$ \\
${ }^{90} \mathrm{Y}$ & beta & 2.67 & 12 & 2,284 \\
${ }^{186} \mathrm{Re} /{ }^{188} \mathrm{Re}$ & beta/gamma & 3.78 & 10 & 1,037 \\
${ }^{177} \mathrm{Lu}$ & beta/gamma & 6.68 & 1 & 497 \\
${ }^{131} \mathrm{I}$ & beta/gamma & 8.04 & 4 & 606 \\
${ }^{111} \mathrm{In}$ & $\begin{array}{l}\text { Auger/gamma } \\
\text { beta }\end{array}$ & 2.8 & $0.55 / 0.01$ & $245 / 175$ \\
${ }^{32} \mathrm{P}$ & 14.28 & 8.1 & 1,700 \\
${ }^{89} \mathrm{Sr}$ & beta & 50.5 & 8 & 2,284 \\
\hline
\end{tabular}




\section{Penetration Range}

Cell death is achieved by irreversible DNA damage, and therefore the target for the therapy is the cell nucleus [9]. Biological effects are determined by the linear energy transfer or energy lost per unit distance as an ionizing particle travels through a material. This varies depending on the speed and charge of the particle involved. In general, alpha particles are heavy and relatively slow moving and have a much higher linear energy transfer than beta particles or gamma rays. High linear energy transfer radiation can deposit most of its energy within the volume of one cell and the chance of DNA damage is therefore larger, so that the biological effect is generally greater than for radiation with low linear energy transfer.

\section{Radiation Half-Life}

The physical half-life relates to the rate at which an absorbed radiation dose is delivered: it is a fixed property of the radionuclide. A short half-life (high dose rate) is suitable for rapidly dividing cells. A lower rate (and longer half-life) may be suitable for more indolent malignancies [10].

\section{Specific Emitters in Use in Therapy}

${ }^{131}$ I is the most widely available radionuclide, used for targeting thyroid tissue (which selectively concentrates iodine) and for labelling metaiodobenzylguanidine (MIBG) (see below) and proteins. Early studies in neuroendocrine tumours frequently used indium ( ${ }^{111} \mathrm{In}$ )-labelled ligands. The cytotoxic effect may be linked to Auger emissions as the emitter has to be internalised for short-range conversion electrons to reach the nucleus [11]. For pure beta emitters such as yttrium $\left({ }^{90} \mathrm{Y}\right)$, the range of the emitted particle is greater than the diameter of the cell and may result in crossfire involving neighbouring cells [5]. Lutetium $\left({ }^{177} \mathrm{Lu}\right)$ emits a shorter range, lower energy beta particle suitable for smaller tumours, and in addition emits gamma radiation [6], facilitating imaging after therapy. The properties of these, together with other emitters used to treat non-endocrine pathologies, are summarised in table 2.

\section{Features of the Radiopharmaceutical}

Properties of the carrier molecule or ligand determine the biodistribution and characteristics of the radiolabelled therapeutic compound. Suitable compounds include:

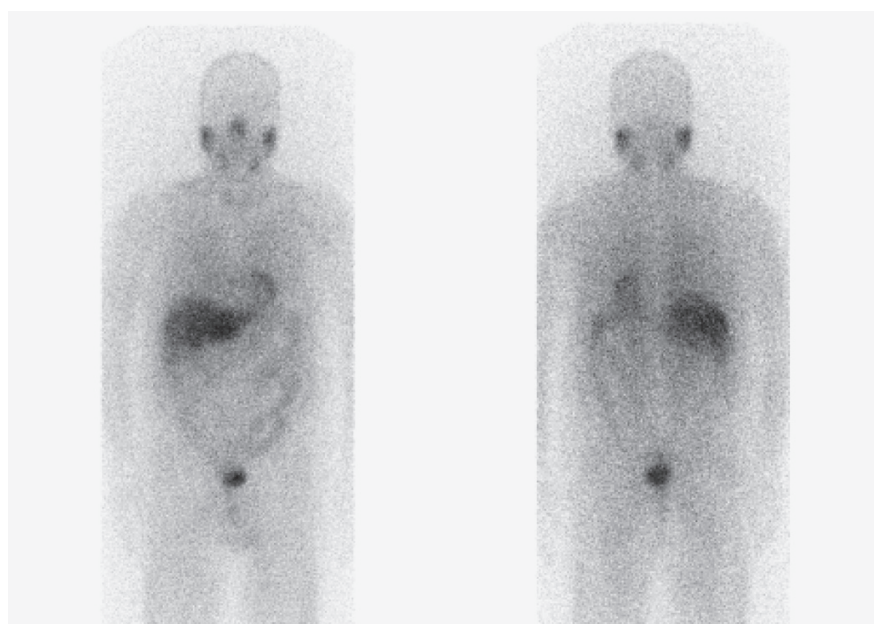

Anterior

Posterior

Fig. 1. Normal ${ }^{123}$ I-MIBG anterior and posterior whole body scan showing physiological salivary gland, myocardial and hepatic uptake with renal and gastrointestinal excretion. ${ }^{123} \mathrm{I}-\mathrm{MIBG}$ is also usually taken up by the adrenal glands.

- Substances taken up by the target cell for use in metabolic processes - for example, iodine in thyroid tissue, MIBG for adrenomedullary tissue [12, 13] (fig. 1).

- Substances which bind cell-surface receptors in the tissue of interest. The ligand-receptor complex may stay on the cell surface or may be internalised - for example, somatostatin analogues which bind to somatostatin receptors on some neuroendocrine tumours [14] (fig. 2).

The targeting substance may be labelled directly (as in the case of ${ }^{131} \mathrm{I}$ ) or may be linked to a radionuclide by means of a stable connection in the form of a chelator. The pharmacokinetics of the radiopharmaceutical is influenced by chelator properties [15], final molecular structure, receptor affinity and lipophilic properties. These properties and the radiation half-life of the radionuclide (which is a fixed property) [10] determine the total dose of radioactivity delivered to the tumour. 


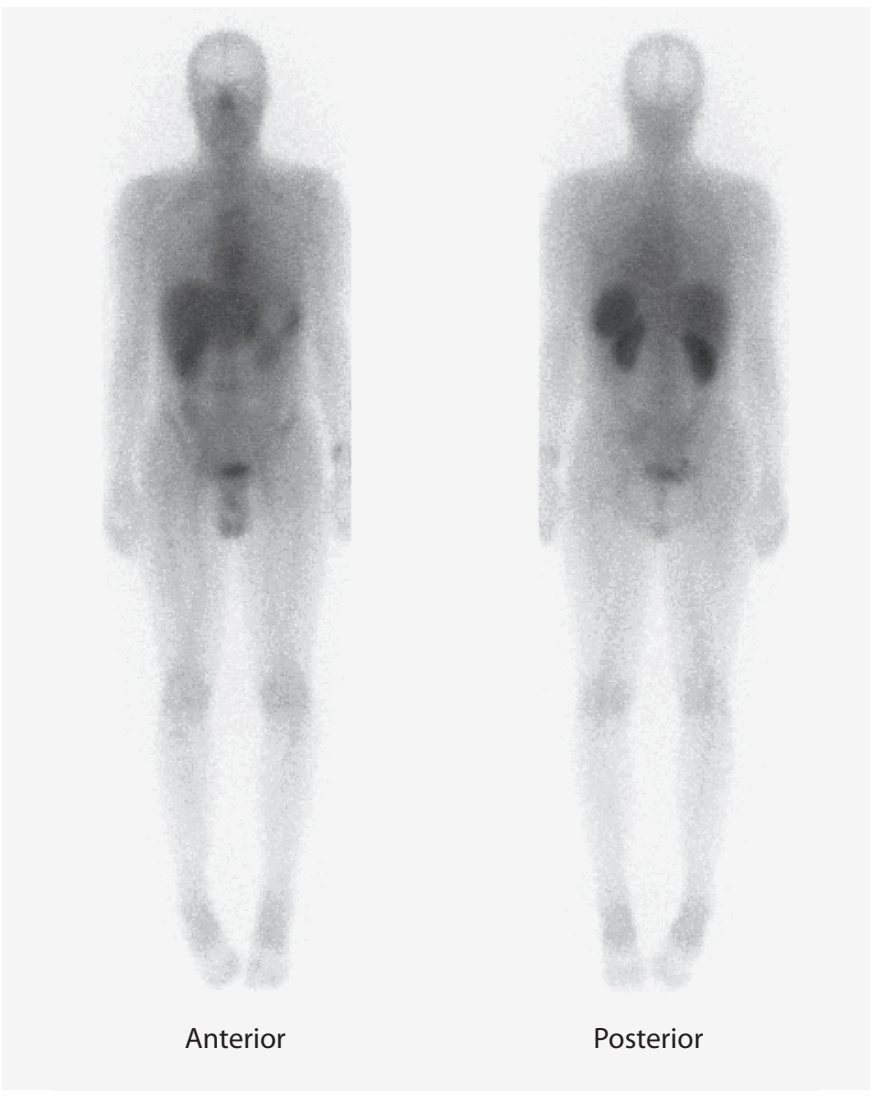

Fig. 2. Normal ${ }^{111}$ In-octreotide anterior and posterior whole body scan showing physiological uptake in the liver, spleen and kidneys with renal and gastrointestinal excretion. ${ }^{111}$ In-octreotide may also be also taken up by the thyroid gland.

\section{Features of the Disease Process}

The extent and distribution of the disease and the rate of cell division can influence the effectiveness of targeted radionuclide therapy. For example, in the case of somatostatin analogues, successful tumour-targeting depends on affinity of the radiopharmaceutical to surface receptors. This requires sufficient cellular differentiation within the tumour for continued expression of the receptors. It has been postulated that a difference in response between primary tumour and metastases may be due to differential expression of somatostatin receptor subtypes [6]. Preclinical studies have demonstrated a greater tumour response in small tumours compared to large ones [16]. In large end-stage tumours, the tissue is often poorly vascularised with central necrosis, and uptake and penetration of the therapeutic agent can be variable [10]. The site of the tumour is also significant, as the proxim-
Table 3. Examples of patient selection criteria for targeted radiotherapy

Indications

Inoperable/metastatic GEP

Good performance status: self-caring

Radiopharmaceutical uptake at all known tumour sites

Minimum haematological and biochemical criteria

$\mathrm{Hb}>10 \mathrm{~g} / \mathrm{l}$

$\mathrm{Wcc}>3 \times 10^{9} / 1$

Plt $>100 \times 10^{9} / 1$

Urea $<10 \mathrm{mM}$

Creatinine $<160 \mu \mathrm{M}$

GFR $>40 \mathrm{ml} / \mathrm{min}$

Absolute contraindications

Pregnancy/lactation

Inability to comply with radiation protection instructions

Unmanageable urinary incontinence

Precautions

Myelosuppression

Bone marrow metastases

Renal impairment

Extensive hepatic involvement

Chemotherapy in preceding 6 weeks

Poor performance status/not self-caring

ity of the tumour to radiosensitive tissues is important. Patients receiving radiolabelled somatostatin analogues who have extensive hepatic involvement and high uptake on octreotide scanning are at greater risk of developing fulminant hepatic necrosis [17]. If there is metastatic infiltration of the bone marrow, then therapy can exacerbate bone marrow failure [13].

\section{Features of the Patient}

The suitability of patients for targeted radionuclide therapy is influenced by several factors. Clearly, as a first step the patient must have disease amenable to this therapy. Current evidence mainly comes from retrospective analysis of subgroups of treatment-responders in nonblinded, non-randomised trials. There are practical considerations and constraints, such as a willingness to be admitted to hospital for treatment and be well enough to be managed within radiation protection guidelines. High dependence on nursing or other daily care may be problematic. Previous treatments given, such as the total dose of radiation already received, may require consideration, 
Table 4. Summary of criteria for classification of response to treatment in malignancy according to World Health Organisation guidelines, RECIST criteria and integrated response of tumour load, hormone status and clinical symptoms

\begin{tabular}{llll}
\hline $\begin{array}{l}\text { Response } \\
\text { category }\end{array}$ & $\begin{array}{l}\text { WHO tumour } \\
\text { response }\end{array}$ & RECIST tumour criteria & Amalgamated information for response assessment \\
\hline $\mathrm{CR}$ & $\begin{array}{l}\text { disappearance of } \\
\text { tumour confirmed } \\
\text { at } 4 \text { weeks }\end{array}$ & $\begin{array}{l}\text { disappearance of all target } \\
\text { lesions }\end{array}$ & $\begin{array}{l}\text { complete regression of all clinical and hormonal evi- } \\
\text { dence of tumour including radiological abnormalities }\end{array}$ \\
\hline PR & $\begin{array}{l}\text { 50\% reduction in } \\
\text { sum of the products of } \\
\text { the perpendicular } \\
\text { diameter of measurable } \\
\text { lesions }\end{array}$ & $\begin{array}{l}30 \% \text { decrease in the sum of } \\
\text { the longest diameter of target } \\
\text { lesions }\end{array}$ & $\begin{array}{l}\text { 30\% decrease in the sum of the longest diameter of tar- } \\
\text { get lesions, some clinical and/or hormonal improvement }\end{array}$ \\
\hline nD & $\begin{array}{l}\text { neither PR or PD } \\
\text { criteria met }\end{array}$ & neither PR or PD criteria met & $\begin{array}{l}\text { less than 50\% reduction or no greater than 25\% increase } \\
\text { in measurable tumour, hormonal measurement and } \\
\text { symptoms }\end{array}$ \\
\hline PD & $\begin{array}{l}25 \% \text { increase in } \\
\text { tumour size }\end{array}$ & $\begin{array}{l}20 \% \text { increase in the sum of } \\
\text { the longest diameter of target } \\
\text { lesions }\end{array}$ & $\begin{array}{l}\text { progressive disease: appearance of new lesions or an in- } \\
\text { crease of 25\% or more in tumour size and hormonal and } \\
\text { symptomatic deterioration }\end{array}$ \\
\hline
\end{tabular}

$\mathrm{CR}=$ Complete response $\mathrm{PR}=$ partial response; $\mathrm{SD}=$ stable disease $\mathrm{PD}=$ progressive disease.

as may previous high-dose chemotherapy [18]. Some selection criteria have been proposed to help define which patients may and may not receive radionuclide therapy (table 3) [19].

\section{Evaluating Response to Treatment in Radionuclide Therapy}

Evaluation of response to treatment is an important part of the decision making process regarding ongoing management. In addition, for the purposes of studies and trials it is important to collect data which can be compared. Responsivity can be subdivided as follows:

1) Symptomatic responses. Resolution of symptoms and quality of life are assessed using validated scores such as Karnofsky performance status (physician assessment) or SF-36 (patient self-assessment). These scales were developed for use in generic illness and have limitations in cancer patients for whom additional specific issues may be relevant. Several questionnaires have been developed for cancers such as the QLQ-30 which uses a Likert scale with add-on modules for specific tumours [20]. A disease-specific module for neuroendocrine tumours is being evaluated [21], although its use has not been reported in studies of radionuclide therapy.
2) Hormonal responses. These are assessed by measures such as urinary 5HIAA, fasting gut peptides or tumour markers such as chromogranin A and CEA.

3) Tumour response. There are various methods to monitor this, including the original World Health Organisation criteria [22]. RECIST criteria provide voluntary, international standards for measuring tumour response, based on measurable disease (i.e. the presence of at least one measurable lesion) in one linear dimension, defining target and non-target lesions [23]. These criteria have recently been revised [24], although the new system has yet to be used in published studies of neuroendocrine tumours. Alternatives are the SWOG criteria, using different measured parameters. In both cases, account is taken of lesion size but not of consistency or necrosis and likely activity [25].

Ideally, integration of all of these factors plays a part in the evaluation of patient response (table 4) [26].

\section{Use of Radionuclide Therapy in Neuroendocrine Tumours}

\section{Phaeochromocytoma and Paraganglioma}

Phaeochromocytomas and paragangliomas are tumours originating from chromaffin tissue, phaeochro- 


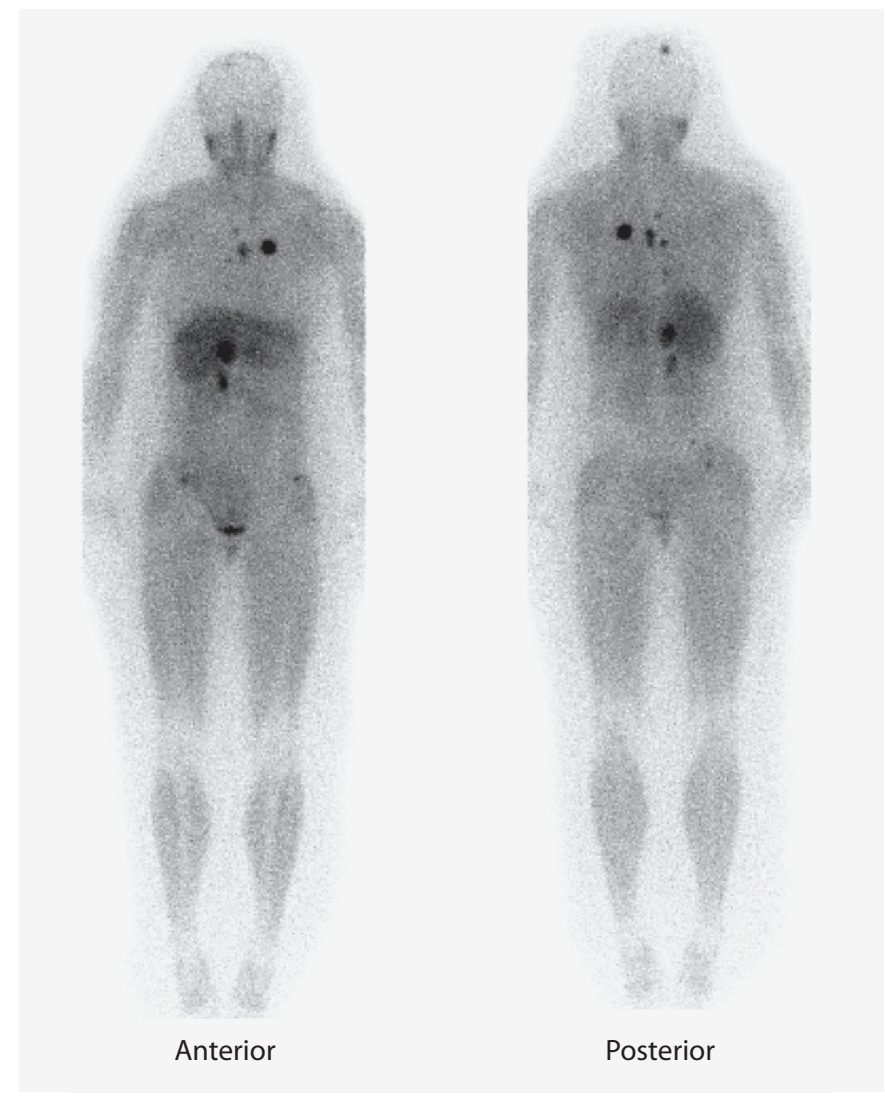

Fig. 3. ${ }^{123}$ I-MIBG anterior and posterior whole body scan showing multi-focal skeletal and soft tissue metastases in a malignant phaeochromocytoma.

mocytoma arising from of the adrenal medulla and paragangliomas from extra-adrenal sites along the sympathetic or parasympathetic chain [27]. MIBG is selectively concentrated by these tumours as well as occasional carcinoid tumours and medullary carcinoma of the thyroid, entering the cells via VMA transporters VMAT1 and 2 [28]. ${ }^{131}$ I-labelled MIBG is used as a therapy for MIBGavid tumours (fig. 3).

Various therapeutic regimens have been described, using activities ranging from 3.7 to $11.1 \mathrm{GBq}$ per administration and a wide range of cumulative administered doses [26]. Suitability for treatment is based on MIBG avidity of the primary tumour and metastases when scanned with MIBG labelled with either ${ }^{123}$ I or ${ }^{131}$ I. More recently, quantification of expression of VMAT 1 and 2 in surgical specimens has been used as a means of predicting likely response to therapy [29]. Several treatments may be required at intervals of 3-6 months to obtain an objective response.
A retrospective analysis of 37 patients receiving ${ }^{131} \mathrm{I}-$ MIBG therapy in a single institution for various indications demonstrated that $82 \%$ of the patients receiving MIBG alone and $84 \%$ of those receiving additional therapy had stable disease for a median follow-up period of 32 months [13]. Of these, 8 patients had metastatic phaeochromocytoma (of whom 3 showed no response of the tumour, 3 had a partial response and 2 responded initially and then progressed). Several patients showed improvement in symptoms and hormonal markers. The significance of the findings is difficult to interpret in the absence of a control group, particularly as in many such cases the natural history of disease is of very slow progression. In a summary of cumulative responses to treatment in a total of 23 studies comprising a total of 166 patients, with a wide range of total activities (administered as a series of treatments), there was a complete response on imaging criteria in $4.2 \%$, a partial response in $25.3 \%$, stable disease in $43.4 \%$ and disease progression in $22.9 \%$ (a further $4.2 \%$ did not have a tumour response recorded). Of these patients, 125 had documentation on the hormonal response to the tumour: of these, $16.8 \%$ with values recorded (12.7\% of the 166 total) had disease progression and the remainder had complete or partial response or stable disease. Again, interpretation of the results is limited by the absence of a comparison group either untreated or to compare with 'current best treatment' [27]. Overall, for the majority of patients, MIBG therapy is not a curative intervention. The impact of the timing of the treatment during the natural history of the disease and the effects of combining this radionuclide treatment with other modalities (such as the use of MIBG as an adjuvant treatment for eradication of residual disease after surgery) are under investigation. Uncertainty remains over the relative merits of single high-dose MIBG treatment versus multiple treatments each of lower activity [30-32]. Reported side effects of MIBG therapy depend on the activity, whole body dose and distribution of disease. They may include nausea, vomiting and transient myelosuppression (particularly for patients with marrow infiltration with tumour at the time of the therapy) [10]. The risk of development of second malignancies after treatment remains uncertain. These are reported in children treated with ${ }^{131}$ I-MIBG for neuroblastomas [33], but here the additional contribution of MIBG was difficult to separate from other therapies also used, including exposure to high-dose combination chemotherapy, external beam radiation and total body irradiation prior to transplantation. 


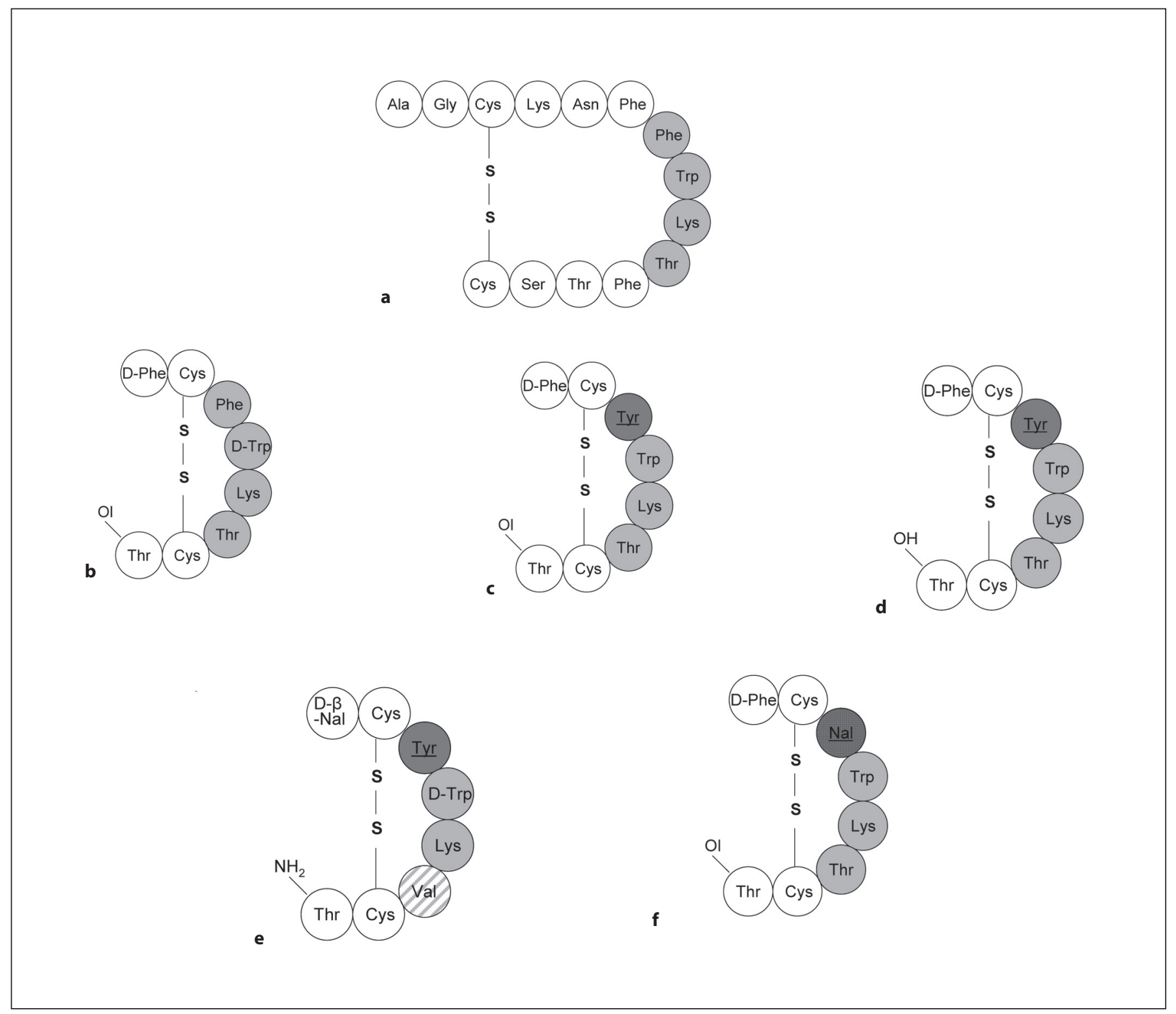

Fig. 4. Primary and secondary structures of somatostatin and some somatostatin analogues in therapeutic use. a Somatostatin amino acid sequence. b Octreotide amino acid sequence. $\mathbf{c} \mathrm{Tyr}^{3}$-octreotide amino acid sequence. d $\mathrm{Tyr}^{3}$-octreotate amino acid sequence. e Lanreotide amino acid sequence. $\mathbf{f}$ DOTA-NOC sequence.

In addition to MIBG avidity, chromaffin cell tumours also frequently express somatostatin receptors, although of the five subtypes of somatostatin receptor, SSTR2 are expressed less on chromaffin cell tumours than on gastrointestinal and pancreatic neuroendocrine tumours. This is relevant if therapy with radiolabelled somatostatin analogues is considered, as somatostatin analogues have highest affinity for this receptor subtype [34]. Somatostatin analogues have been used in the treatment of phaeochromocytoma, although the reported numbers are low [35].

\section{Gastroenteropancreatic Neuroendocrine Tumours}

Gastroenteropancreatic neuroendocrine tumours (GEP-NETs) comprise a heterogeneous group of pathologies arising from the diffuse endocrine system. This system includes endocrine glands, endocrine islets within glandular tissue and disseminated endocrine cells situ- 
Table 5. Affinity $\left(\mathrm{IC}_{50}\right)$ of radiopharmaceuticals targeting SSTR

\begin{tabular}{llllll}
\hline Radiopharmaceutical & SSTR1 & SSTR2 & SSTR3 & SSTR4 & SSTR5 \\
\hline Native SS-28 & 5.2 & 2.7 & 7.7 & 5.6 & 4.0 \\
${ }^{111}$ In-DTPA-octr & low/no affinity & 22 & 182 & low/no affinity & 237 \\
${ }^{90}$ Y-DOTA-Tyr ${ }^{3}$-octreotide & low/no affinity & 20 & 27 & low/no affinity & 57 \\
${ }^{177}$-Lu-DOTA-Tyr ${ }^{3}$-octreotate & low/no affinity & 1.5 & low/no affinity & 453 & 547 \\
${ }^{90}{ }^{\text {Y-DOTA-lanreotide }}$ & 154 & 23 & 1.5 & 2.5 & 0.45 \\
${ }^{111}$ In-DOTA-NOC & low/no affinity & 2.9 & 8 & low/no affinity & 11.2 \\
\hline
\end{tabular}

Adapted from references [34, $\left.72^{\mathrm{a}}, 73^{\mathrm{b}}\right]$. Values for IC50 not directly comparable across peptides as not all evaluated in identical experimental conditions. Number of experiments and SEM not shown here to aid clarity.

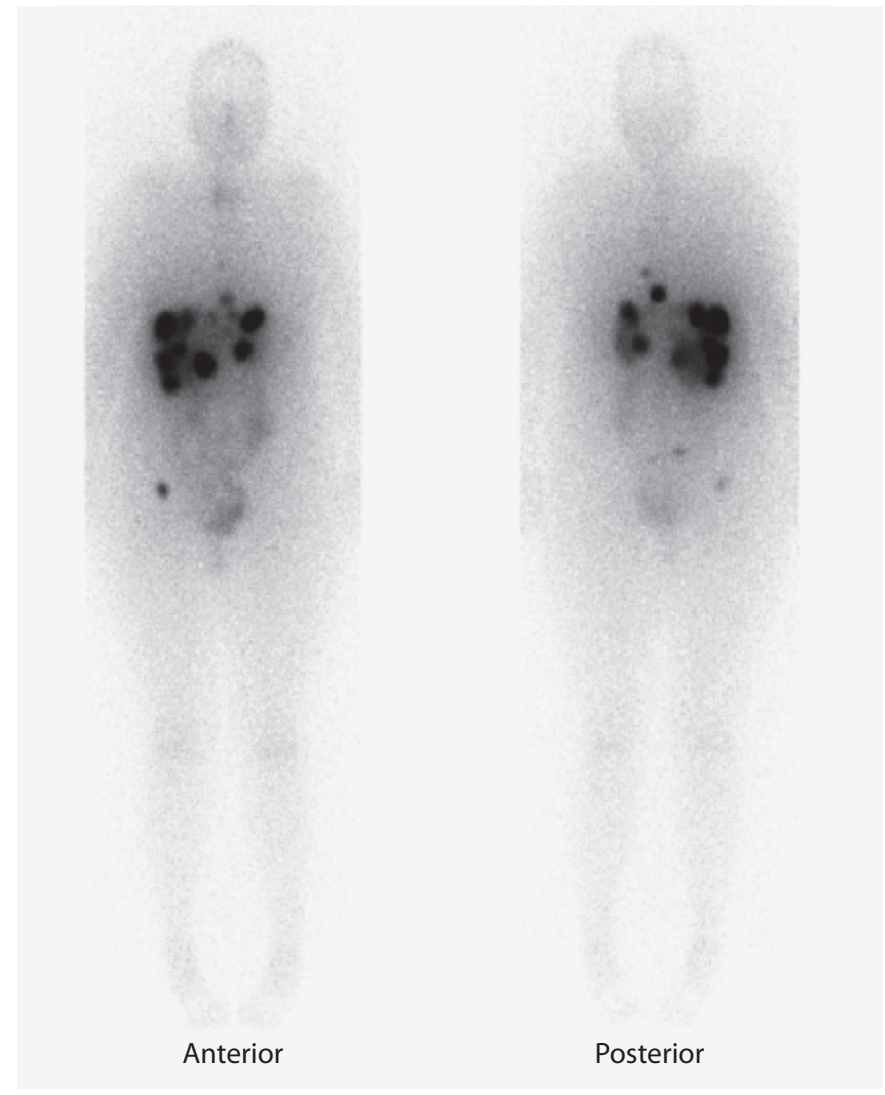

Fig. 5. ${ }^{111}$ In-octreotide anterior and posterior whole body scan showing somatostatin receptor-positive hepatic and skeletal metastases from a midgut carcinoid tumour. Tumour uptake is significantly higher than background activity, indicating a favourable therapeutic ratio for high activity treatment. ated among exocrine cells $[19,36]$. The tumours include those arising from the endocrine cells within the respiratory and gastrointestinal tracts, known as 'carcinoid' tumours. These have been classified as foregut, midgut and hindgut according to their presumed embryological origins. Such tumours can occur sporadically or as part of familial syndromes, and their biological behaviour can vary significantly [37]. Also included are islet cell tumours arising from the pancreas. GEP-NETs are often well differentiated, retaining expression of cell-surface somatostatin receptors [38].

There are 5 major subtypes of somatostatin receptors which bind the 14-amino-acid peptide somatostatin and its high-affinity 28-amino-acid precursor [39-41]. Receptor-binding affinities for both native peptides and synthetic somatostatin analogues differ considerably, as examined in vitro [34], via mouse organ uptake [42] and via scintigraphy studies in patients with neuroendocrine tumours [43]. The receptors are differentially expressed on different tumours, but the commonest subtypes expressed are SSTR2 and 5 [26], providing a potential target for treatment [5]. The half-life of somatostatin is short, but several analogues of somatostatin are available which are more resistant to plasma degradation while retaining a similar biological profile [44], including octreotide (Novartis, Basel, Switzerland) and lanreotide (Ipsen, Paris, France; fig. 4). Others described include octreotate, NOC and BOC. Most of these have high affinity for SSTR2 and to a lesser extent SSTR5, with some binding also to SSTR3 (table 5). As most GEP tumours are known to predominantly express SSTR2, clinical studies have utilised radiolabelled somatostatin analogues with a high affinity for this receptor [45]. Binding results in formation of a receptor-peptide complex which is then internalised into 
the cell (fig. 5). This promotes retention of the radionuclide in the tumour while the remaining free molecules are rapidly cleared from the bloodstream [46]. The differences in molecular structure may affect renal clearance as well as receptor affinity, and this balance may modulate the side effect profile. For example, Tyr ${ }^{3}$-octreotate has higher tumour but similar kidney uptake to $\mathrm{Tyr}^{3}$-octreotide, thus improving the tumour:kidney ratio. However, Tyr ${ }^{3}$-octreotide is cleared more rapidly by the kidney, and it has been suggested that this may reduce bone marrow irradiation [16].

In order to enable labelling of the peptide with a radiometal, the peptide ligand is bound to a chelator, such as tetraazacyclododecanetetraacetic acid (DOTA) and diethylene-triamenepentoacetic acid (DTPA; fig. 6). The ligand-receptor affinity profile is modulated by the chelator and this in turn affects efficacy [34]. The properties and stability of the chelator-ligand complex can also affect the type of radionuclide with which it can be labelled.

With this theoretical background in mind, a small number of therapeutic peptide complexes have been administered to patients, specifically: DTPA-octreotide labelled with indium, DOTA-D-Phe-Tyr ${ }^{3}$-octreotide (DOTATOC) labelled with yttrium, DOTA-D-Phe-Tyr ${ }^{3}$ octreotate (DOTATATE) labelled with lutetium, DOTAlanreotide (DOTALAN) labelled with yttrium and indium-labelled DOTA-NOC (table 4). The data available on the use of these agents in GEP-NETs will be discussed individually. Patient data for the various agents available are limited as are comparative data to assess their relative merits. For practical reasons, these agents have not been subject to randomised trials and the use of different protocols prevents direct comparison of results between centres.

\section{${ }^{111}$ Indium-Octreotide}

Experience with indium-octreotide ( ${ }^{111} \mathrm{In}$-octreotide) is described in a few series. The effects of ${ }^{111} \mathrm{In}$-octreotide in 30 patients with end-stage tumours of variable pathology (of which 21 were GEP-NETs) suggested an outcome dependent on the cumulative activity received. Seven patients received a total activity of less than $20 \mathrm{GBq}$ and all developed progressive disease, while 21 patients received greater than $20 \mathrm{GBq}-6$ had partial shrinkage and 8 had stabilisation of their tumour. There were no specific side effects reported apart from a transient decrease in white cell count. Pituitary and pancreatic islet cells (both known to express somatostatin receptors) did not change during the course of follow-up [5].

A later series reviewed 50 patients, 30 men and 20 women, of whom 26 had somatostatin-receptor-positive

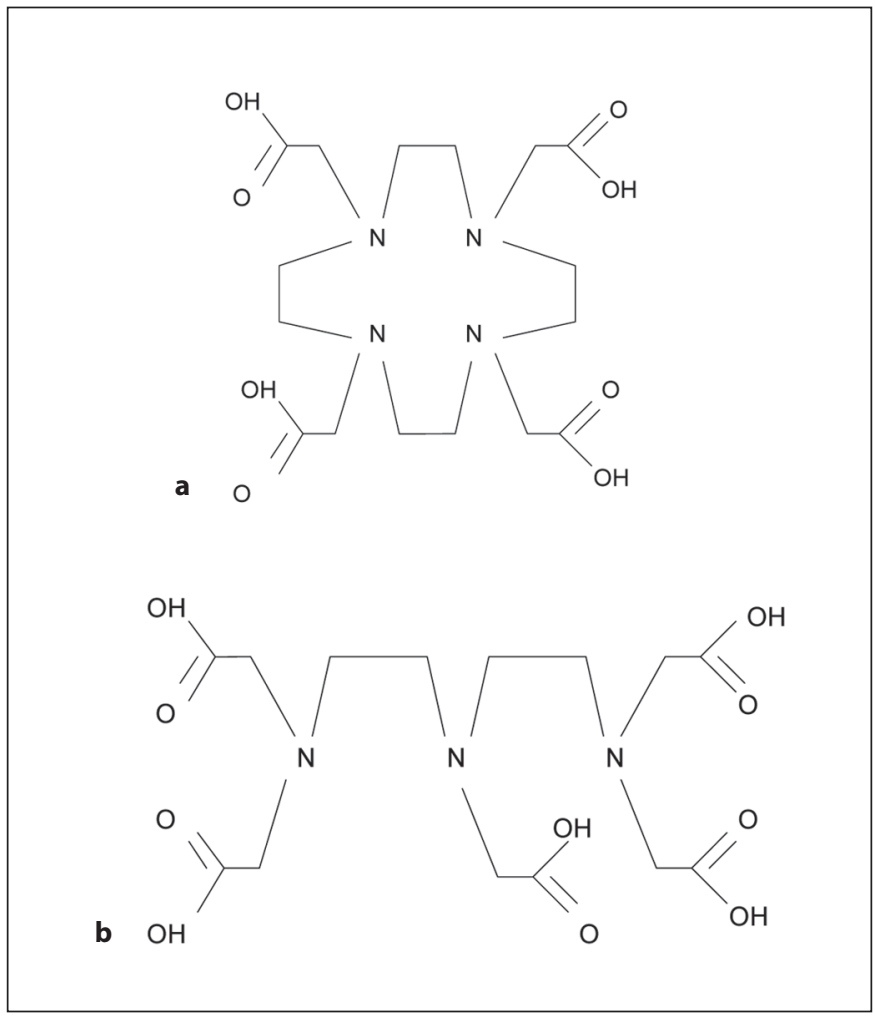

Fig. 6. Molecular structure of some chelators used to couple radiolabelled octreotide analogues. a DOTA. b DTPA.

GEP-NETs, with 24 progressive prior to enrolment. The cumulative activity administered was $20-160 \mathrm{GBq}$ and outcomes were 1 partial remission, 6 'minor remissions' and 14 instances of stable disease. Administration of the related agent ${ }^{111}$ In-pentetreotide (containing a synthetic polypeptide derived from octreotide and linked to the chelator DTPA) to 27 patients, mainly with carcinoid from various sites of origin (6.7-46.6 GBq cumulative activity), resulted in a $62 \%$ symptom response (on the basis of Karnofsky score, pain and amount of supportive drugs taken) and an 81\% hormonal response (on the basis of measured CgA subunit) with claims of no major side effects but with a prolongation of survival - although only with comparison to historical data [47]. In 16 patients (of whom 12 had GEP-NETS) receiving ${ }^{111}$ In-octreotide with a longer period of follow-up, the outcome challenged the long-term efficacy of the therapy. Seventy percent of the total seemed to derive some benefit for 6 months after the last treatment, with $31 \%$ having a sustained benefit at 18 months, but the mean progression-free survival for the patients with GEP-NETs was only 6.25 months [48]. 
Fig. 7. Sequential ${ }^{111}$ In-octreotide anterior whole body scans before treatment (a), 6 months after treatment (b) and 12 months after treatment (c) showing a progressive reduction in somatostatin receptor-positive tumour burden in malignant paraganglioma.

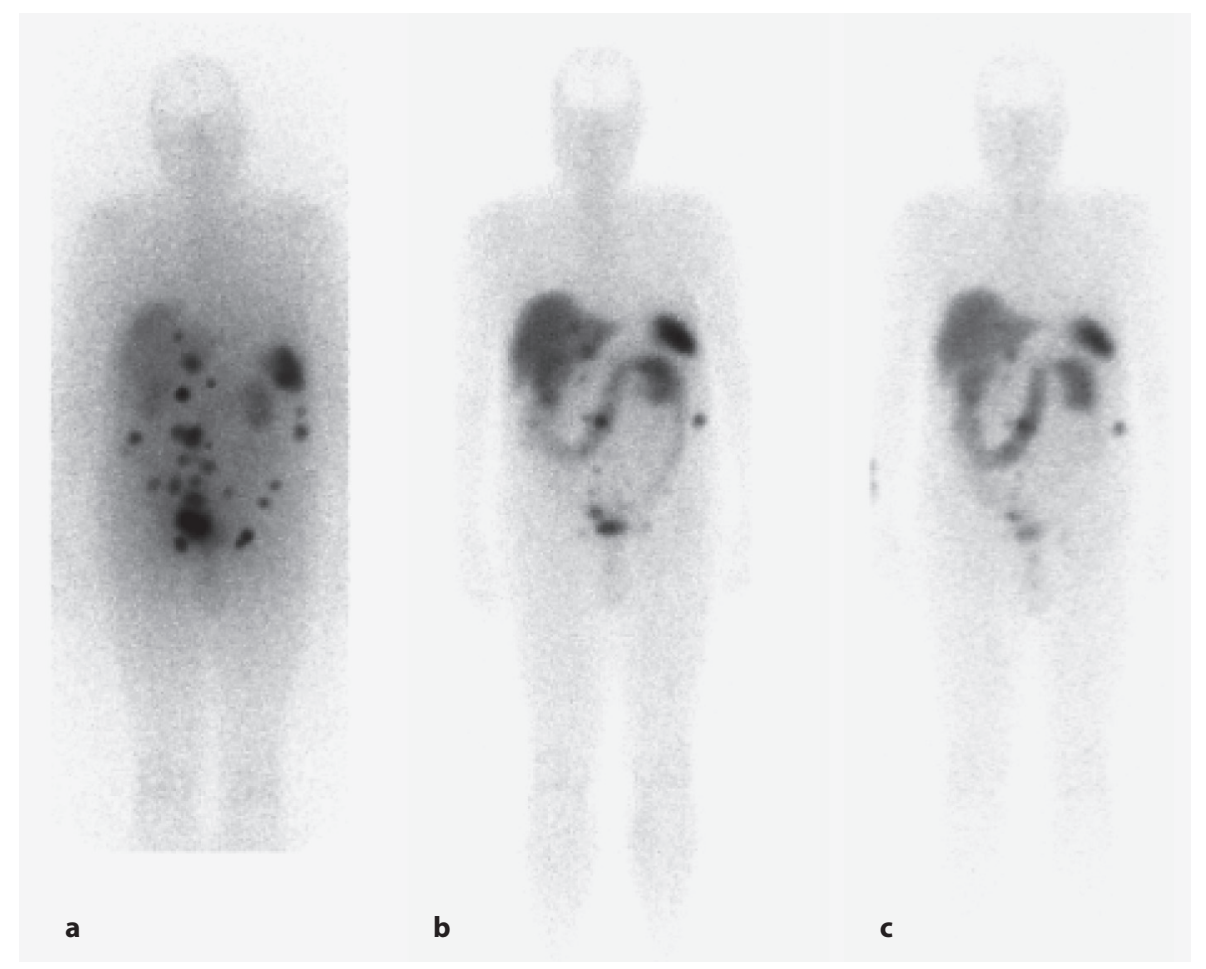

Overall, while the clinical and biochemical data initially seemed encouraging (fig. 7), robust evidence of objective tumour regression was limited, leading to a search for more data and better therapeutic agents.

\section{${ }^{90}$ Yttrium-DOTA-TOC ${ }^{90}$ Yttrium-Tyr ${ }^{3}$-Octreotide)}

Preliminary results came from the treatment of a heterogeneous patient cohort comprising 29 patients with somatostatin-receptor-positive tumours with varying histology. Patients received single treatments at 6-week intervals (and average cumulative activity of $6,120 \mathrm{MBq} /$ $\mathrm{m}^{2}$ ). Twenty patients had stable disease, 2 had partial remission, 4 had a reduction in tumour mass of $<50 \%$ and 3 were progressive. Five patients developed haematological or renal toxicity having received a cumulative activity $>7.4 \mathrm{GBq} / \mathrm{m}^{2}$ [49]. A phase II trial with a limited cumulative dose given to 41 patients, including GEP-NETs but also with tumours of bronchial and unknown origin, in whom $82 \%$ had treatment-resistant or progressive disease at the outset reported a $24 \%$ tumour response, and the treatment was well tolerated. A complete response was seen in $2 \%$, partial response in $22 \%$, minor response in $12 \%$, stable disease in $49 \%$ and progression in $15 \%$ [50]. In a further study of 39 patients with progressive GEPNET and 3 bronchial carcinoids, four intravenous injec- tions of $7.4 \mathrm{GBq} / \mathrm{m}^{2}{ }^{90} \mathrm{Y}$-DOTATOC were administered at 6 -week intervals with evaluation at 4 weeks before and 8-12 weeks after therapy, using radiology criteria and NCI-CTC questionnaire (which grades symptoms and signs). Compared to historical series of data for progression, symptoms and tumour response for other treatments (such as long-acting somatostatin analogues), the authors reported a $24 \%$ tumour response (36\% response rate for pancreatic NETs). There was no serious toxicity, but $15 \%$ of patients had a carcinoid crisis despite taking high-dose octreotide [51]. Administration of 7.4-20.3 $\mathrm{GBq} / \mathrm{m}^{2}$ to a heterogeneous group of 87 patients with disease which was not necessarily progressive at the time of therapy suggested that with treatment $20 \%$ had progressive disease, while the remainder had complete or partial remission or stable disease [52].

A summary of results from 141 patients treated in Italy receiving a cumulative activity of 7.4-26.4 GBq suggested a total response rate (combining partial plus complete response) of $26 \%$. For patients with progressive disease at the outset, $23 \%$ remained progressive while the rest were stabilised or showed a total or partial response [18]. In a follow-up of 54 patients (of whom 41 had progressive disease at entry) who had received the maximum allowable dose in a previous phase I study (either up to 
$14.8 \mathrm{GBq} / \mathrm{m}^{2}$ in 4 cycles or up to $9.3 \mathrm{GBq} / \mathrm{m}^{2}$ ), 4 had a partial response, 7 a moderate response, 33 stable disease and 10 were progressive [18]. Therapy also improved the quality of life [53]. In a smaller but more recent study, 58 patients with somatostatin receptor-positive GEP-NETs were treated with ${ }^{90}$ Yttrium-DOTATOC. Of these, 52 had liver metastases and 47 had demonstrable progressive disease prior to therapy. In total, $57 \%$ of the subjects showed a beneficial improvement in the progression of disease (for example moving from progressive to stable disease). Overall, patients with a greater tumour burden or progressive disease had worse overall survival than the rest of the cohort. The outcomes were compared with a historical control group of 32 patients with GEP-NET who had been treated with ${ }^{111}$ In-octreotide, with overall survival of 36.7 months in the ${ }^{90} \mathrm{Yttrium}^{-\mathrm{Tyr}^{3} \text {-octreotide }}$ compared to 12 months for the ${ }^{111}$ In-octreotide group, although conclusions based on the use of historical controls must remain guarded [54].

\section{${ }^{90}$ Yttrium-DOTA-Lanreotide}

In contrast to labelled octreotide, this agent has greater affinity for SSTR2 and 5. It also binds SSTR4 with high affinity (although this receptor is less represented in human tissue) and SSTR1 with low affinity [55], and thus its use has been recommended for GEP-NETs. The first report was in a single patient with a metastatic, although not demonstrably progressive, gastrinoma. The author reported 25\% regression of liver metastases and symptomatic improvement, although no biochemical cure [56]. The agent has also been used in a European multicentre study (MAURITIUS) in 154 patients with proven progressive disease. These included 39 GEP tumours of which 34 were of carcinoid type. All patients received 2 cycles initially, then therapy was abandoned if there was no progress or 2 further cycles were administered if effective. Over 3 years of follow-up, 8 patients $(20.5 \%)$ had tumour regression, $17(43.6 \%)$ were stable and $10 \%$ of all the patients had improvement in quality of life measurements (mainly improvement in pain) [57].

\section{${ }^{90}$ Yttrium-DOTA-TATE $\left({ }^{90}{ }^{\text {Yttrium-Tyr }}{ }^{3}\right.$-Octreotate)}

The effects of ${ }^{90}$ Yttrium-DOTA-TATE have been reviewed in a number of phase I trials. There appears to be some benefit, but data comparing either to a placebo control group, a best-alternative treatment group or even to a group receiving a different radiopharmaceutical, are lacking [16]. Of 75 patients treated, 28 had a partial remission and 39 had stable disease, although the disease status prior to treatment was variable [26].

\section{${ }^{177} \mathrm{Lu}$-DOTA-Tyr ${ }^{3}$-Octreotate}

As with yttrium, the use of lutetium labelling was based on the theoretical advantage of beta irradiation of non-octreotide avid areas of tumour close to areas of uptake. The combination with octreotate rather than octreotide favours SSTR2 affinity. This radiopharmaceutical has been administered to patients with carcinoid tumours [58] and also in patients with paraganglioma and meningiomas among others [59]. In 35 patients with GEP tumours of various sizes and a final cumulative radiation dose of 22.2-29.6 GBq, with treatment intervals of 6-9 weeks, at follow-up 3-6 months after administration of the final dose, patients had achieved 3\% remission, 35\% partial remission and $41 \%$ were stable. [17]. In a more extensive study using this agent, efficacy was evaluated in 310 patients with GEP-NETs, while toxicity was evaluated in 504 patients. Patients received a cumulative radiation dose of $27.8-29.6 \mathrm{GBq}$, in approximately 4 treatment cycles with intervals of 6-10 weeks between. Complete remission was seen in $2 \%$, a partial response in $28 \%$ and a minor response (tumour reduction of $25-50 \%$ ) in $16 \%$. The median time to progression was 40 months, with a survival benefit of 40-72 months calculated from the time of diagnosis, compared with historical controls. Haematological toxicity of grade 3 or 4 occurred in $3.6 \%$ of treatment cycles, with serious adverse events of myelodysplastic syndrome in 3 patients and non-fatal liver toxicity in 2 patients [60].

\section{Practical Aspects of Radionuclide Therapy}

\section{Dosimetry and Administration}

Optimal targeted radiotherapy should entail a balance of maximal delivery of radiotherapy to the tumour with minimum damage to normal tissues [61]. Dosimetry methods can be used to calculate dose estimates to both tumour and vulnerable organs prior to treatment and have been used to individualise treatment protocols, but their use in treatment optimisation protocols remains complex and disputed $[18,61]$. There are logistic obstacles as such estimations are time-consuming, involving pharmacokinetic, biodistribution and washout studies with the radiopharmaceutical $[7,61]$. In addition, there are no agreed methods for accurately performing tumour dosimetry and, furthermore, dosimetry-based treatment has not been shown to improve outcome. Ideally, a randomised controlled trial of treatment with and without prior dosimetry may help to resolve the issue, but this too presents logistic difficulties.

Neuroendocrinology 2010;91:1-15 
Effects of Other Treatments on Outcomes of Therapy

Prior treatment with somatostatin or its analogues for symptom control may theoretically block or even downregulate the surface SSTRs. In practice, patients should either discontinue octreotide $24 \mathrm{~h}$ before the treatment, or if on a long-acting injected agent, receive the radiolabelled treatment just before the next dose is due [17]. Further studies are needed to optimise the time off somatostatin analogues prior to therapy and the optimal time to reinstate them after the treatment.

\section{Predictors of Response}

Overall patient response rates have varied across studies for various reasons. There has been a lack of uniform criteria for patient selection $[18,61]$, and it would be helpful to utilise available data to define predictors of good response to treatment and enable exclusion of individuals for whom risks may exceed benefits. Data from GEP tumours [62] would suggest that important predictive features include:

- High uptake on octreotide scintiscanning

- Low tumour load and limited hepatic tumour mass (which has prompted a suggestion that early treatment may be more beneficial than watchful waiting - the 'wait-and-see' approach).

- Good performance status

In addition, there is some evidence of a correlation between dose estimates of tumours and tumour size reduction measured at the end of treatment: the median absorbed dose was 6-fold higher in responding than the non-responding tumours [61]. However, the caveats regarding the use of dosimetry in day-to-day practice have already been outlined.

\section{Side Effects}

Adverse reactions observed after radionuclide therapy can be divided into direct side effects and more delayed effects of radiotoxicity [45]. The direct effects include nausea, vomiting and abdominal pain. These are not specific to the radionuclide and are treatable with anti-emetics or pain medication. The mechanisms may include inflammatory and fibrogenic mediators released by mucosal inflammatory cells. Corticosteroid prophylaxis may be helpful. One percent of patients receiving ${ }^{177} \mathrm{Lu}$-octreotate developed a hormonal crisis after therapy due to release of vasoactive substances from the tumour [63].

Haematological toxicities reported range from transient marrow suppression to more significant impairment. Haematological toxicity of grade 3-4 for haemoglobin, white blood cells and platelets has been reported in up to $15 \%$ [45]. Metastatic bone marrow infiltration may exacerbate bone marrow failure after therapeutic radiation [13]. More serious side effects were reported from a clinical trial in which 50 patients were treated with indium-octreotide [64]. Leukaemia and a myelodysplastic syndrome were reported in 3 patients who had received cumulative activity of over $100 \mathrm{GBq}$ (estimated bone marrow dose of $3 \mathrm{~Gy}$ ). This may be influenced by prior chemotherapy [64].

The kidneys are critical organs, particularly as octreotide is mainly renally excreted $[18,61]$. Toxicity occurs because radiolabelled peptides are filtered and then reabsorbed in the proximal tubule. The tubular cells are relatively radioresistant but the glomeruli are not, and this can lead to thrombotic microangiopathy and renal failure $[61,65]$. The damage is dose-dependent and influenced by renal size and haemodynamics, and is particularly troublesome in small kidneys, which receive a higher radiation dose per $\mathrm{ml}$ [66]. Major contributing factors include the patient's age, pre-existing angiopathy (diabetes and hypertension), and prior exposure to nephrotoxic chemotherapy or ionising radiation. Methods to reduce kidney uptake have been developed $[61,66]$ such as coadministration of the positively charged amino-acids L-lysine or L-arginine which compete with the radiopharmaceutical for reabsorption in the proximal tubule [61, 66].

Patients who have extensive hepatic tumour load are at a theoretical risk of early hepatic failure secondary to radionuclide therapy [17] - this is not thought to be due to necrosis, but probably radiation oedema which damages the few remaining normal hepatocytes. This effect can be ameliorated by a reduction in the cycle dose or steroids. However, in clinical practice it may be difficult to distinguish radiation-induced alteration in liver function from subtle progression of disease.

Neither endocrine dysfunction of the pituitary nor diabetes mellitus has been observed after treatment with radiopharmaceuticals [62], but transient impairment of spermatogenesis has been documented [16].

\section{The Future}

Much work remains to be done on the use of radionuclide therapies for neuroendocrine tumours. Some possible future areas of research are outlined below.

\section{Randomised Controlled Trials}

Randomised controlled trials either of radionuclide therapy compared to other forms of treatment, or for the 
comparison of different types of radionuclide therapy, are currently lacking. There are of course practical obstacles such as the difficulty of 'blinded' treatment arms in these circumstances and the slow growth of these tumours, requiring prolonged follow-up to assess effects of therapy. Also, the rarity of the tumours and the multidisciplinary nature of the organisation of care for these patients can make it difficult to assemble a trial cohort with adequate power. Efforts are ongoing via national and international networks (such as UKINETS and ENETS) to resolve this. Such moves will be aided by the adoption of more uniform approaches to the assessment of response to therapy. This in turn is likely to benefit from technical advances in imaging techniques.

\section{Use of Combination Treatments}

${ }^{90} \mathrm{Y}$ particles have high energy and relatively low range with good deposition of radioactivity in tumour cells and good crossfire throughout the tumour, with a short halflife leading to a high dose rate. ${ }^{177} \mathrm{Lu}$ has a lower energy and a shorter particle range and the decay energy is therefore likely to be better absorbed within smaller tumours. Therefore, to treat patients with heterogeneous tumours of variable sizes, the use of a mixture has been proposed. Animal studies suggest that this theoretical advantage is evident in vivo [67] and fits with a mathematical predictive model [68]. Early data for the use of the combination appear promising in terms of effect on median survival in patients with diffuse neuroendocrine tumours and larger studies are anticipated [69]. Where there is avidity for more than one ligand, combination therapy remains an attractive proposition, for example ${ }^{131} \mathrm{I}-\mathrm{MIBG}$ therapy and ${ }^{90}$ Y-DOTATATE.

\section{Timing of Treatment}

Some patient series have shown better responses to treatment when tumour load is lower. Early treatment with radionuclide therapy may therefore be associated with a better outcome that a 'wait-and-see' approach. Future studies should address the optimal time for treatment. Another argument in favour of early treatment is that NETs can de-differentiate during the course of disease and lose expression of SSTRs, at which point targeted radionuclide therapy (if felt to be useful) may become impossible.

\section{Development of New Ligands Combined with New}

Emitters

New SST analogues are in development which may be combined with different emitters and these may have po- tential for radiolabelling [44]. There are new drugs which interact with and lead to cross talk between different receptors either in the same or different families. The resultant SST sub-type homo- or heterodimers may exert properties distinct from the individual receptors in terms of internalisation and functional activity [44]. GEP tumours also express receptors from other families such as the GLP-1 receptor and VIP receptor [46]. A further possible treatment approach may therefore be multireceptor targeting using a mixture of both ligands and emitters. Given the relative rarity and heterogeneity of the patient groups, robust analysis of the efficacy of such agents is likely to be difficult.

\section{Coadministration of Adjuvant Agents or \\ Radiosensitisers}

Radiopharmaceuticals can be made from molecules hybridised to agents with allied functions. For example, Arg-Gly-Asp peptides have been combined with labelled octreotate to bind to specific receptors on newly formed blood vessels for anti-angiogenic properties. Furthermore, coadministration of chemotherapy agents with radiosensitising capability may improve therapeutic efficacy [70]. Such therapy could be combined with immunomodulating agents or with the possibility of gene transfer of genes encoding SSTRs to receptor-negative tumours to render them amenable to the actions of radiopharmaceuticals [44, 71]. There may also be other developments to induce upregulation of SSTRs to enable therapy.

\section{Integrated, Multidisciplinary Approach to Therapy}

Cancer patients greatly benefit from an integrated and multidisciplinary approach to their care. This model is being extended to the care of patients with neuroendocrine tumours, and it is hoped that this will lead to improvements in quality of life.

References
1 Rufini V, Calcagni ML, Baum RP: Imaging of neuroendocrine tumors. Semin Nucl Med 2006;36:228-247.

$\checkmark 2$ Mothersill C, Seymour CB: Targeted radiotherapy: is the 'Holy Grail' in sight? J Nucl Med 2006;47:899-900.

3 Mothersill C, Seymour C: Radiation-induced bystander and other non-targeted effects: novel intervention points in cancer therapy? Curr Cancer Drug Targets 2006;6: 447-454. 
4 Podoloff DA: Diagnostic and therapeutic applications of radiolabeled somatostatin analogs: current status in an oncology center. Curr Pharm Des 2002;8:1809-1814.

5 Krenning EP, de Jong M, Kooij PP, Breeman WA, Bakker WH, de Herder WW, van Eijck CH, Kwekkeboom DJ, Jamar F, Pauwels S, Valkema R: Radiolabelled somatostatin analogue(s) for peptide receptor scintigraphy and radionuclide therapy. Ann Oncol 1999; 10(suppl 2):S23-S29.

6 de Jong M, Kwekkeboom D, Valkema R, Krenning EP: Radiolabelled peptides for tumour therapy: current status and future directions. Plenary lecture at the EANM 2002. Eur J Nucl Med Mol Imaging 2003;30:463469.

7 Kassis AI, Adelstein SJ: Radiobiologic principles in radionuclide therapy. J Nucl Med 2005;46(suppl 1):4S-12S.

8 International Union of Pure and Applied Chemistry. 2008 Compendium of Chemical Terminology Internet edition.

-9 Kassis AI: Radiotargeting agents for cancer therapy. Expert Opin Drug Deliv 2005;2: 981-991.

10 Lewington VJ: Targeted radionuclide therapy for neuroendocrine tumours. Endocr Relat Cancer 2003;10:497-501.

-11 Capello A, Krenning EP, Breeman WA, Bernard BF, de Jong M: Peptide receptor radionuclide therapy in vitro using [111InDTPA0]octreotide. J Nucl Med 2003;44: 98-104.

12 Royal College of Physicians: Radioiodine in the management of benign thyroid disease. A4 report, June 2007. http://www.rcplondon. ac.uk/pubs/contents/0621b67a-4880-4a1b9942-57a666efee4a.pdf.

13 Mukherjee JJ, Kaltsas GA, Islam N, Plowman PN, Foley R, Hikmat J, Britton KE, Jenkins PJ, Chew SL, Monson JP, Besser GM, Grossman AB: Treatment of metastatic carcinoid tumours, phaeochromocytoma, paraganglioma and medullary carcinoma of the thyroid with (131)I-meta-iodobenzylguanidine [(131)I-mIBG]. Clin Endocrinol (Oxf) 2001;55:47-60.

$\checkmark 14$ Krenning EP, Teunissen JJ, Valkema R, deHerder WW, deJong M, Kwekkeboom DJ: Molecular radiotherapy with somatostatin analogs for (neuro-)endocrine tumors. J Endocrinol Invest 2005;28:146-150.

-15 Krenning EP, Kwekkeboom DJ, Valkema R, Pauwels S, Kvols LK, de Jong M: Peptide receptor radionuclide therapy. Ann N Y Acad Sci 2004;1014:234-245.

- 16 de Jong M, Valkema R, Jamar F, Kvols LK, Kwekkeboom DJ, Breeman WA, Bakker WH, Smith C, Pauwels S, Krenning EP: Somatostatin receptor-targeted radionuclide therapy of tumors: preclinical and clinical findings. Semin Nucl Med 2002;32:133140.

-17 Kwekkeboom DJ, Mueller-Brand J, Paganelli G, Anthony LB, Pauwels S, Kvols LK, O’Dorisio TM, Valkema R, Bodei L, Chinol M, Maecke HR, Krenning EP: Overview of results of peptide receptor radionuclide ther- apy with 3 radiolabeled somatostatin analogs. J Nucl Med 2005;46(suppl 1):62S-66S. -18 Bodei L, Cremonesi M, Grana C, Rocca P,
Bartolomei M, Chinol M, Paganelli G: Receptor radionuclide therapy with 90Y[DOTA] 0-Tyr3-octreotide (90Y-DOTATOC) in neuroendocrine tumours. Eur J Nucl Med Mol Imaging 2004;31:1038-1046.

19 Kaltsas GA, Besser GM, Grossman AB: The diagnosis and medical management of advanced neuroendocrine tumors. Endocr Rev 2004;25:458-511.

20 Aaronson NK, Ahmedzai S, Bergman B, Bullinger M, Cull A, Duez NJ, Filiberti A, Flechtner H, Fleishman SB, de Haes JC: The European Organization for Research and Treatment of Cancer QLQ-C30: a quality-oflife instrument for use in international clinical trials in oncology. J Natl Cancer Inst 1993;85:365-376.

21 Davies AH, Larsson G, Ardill J, Friend E, Jones L, Falconi M, Bettini R, Koller M, Sezer O, Fleissner C, Taal B, Blazeby JM, Ramage JK: Development of a disease-specific Quality of Life questionnaire module for patients with gastrointestinal neuroendocrine tumours. Eur J Cancer 2006;42:477-484.

-22 Miller AB, Hoogstraten B, Staquet M, Winkler A: Reporting results of cancer treatment. Cancer 1981;47:207-214.

23 Therasse P, Arbuck SG, Eisenhauer EA, Wanders J, Kaplan RS, Rubinstein L, Verweij J, Van Glabbeke M, van Oosterom AT, Christian MC, Gwyther SG: New guidelines to evaluate the response to treatment in solid tumors. European Organization for Research and Treatment of Cancer, National Cancer Institute of the United States, National Cancer Institute of Canada. J Natl Cancer Inst 2000;92:205-216.

24 Eisenhauer EA, Therasse P, Bogaerts J, Schwartz LH, Sargent D, Ford R, Dancey J, Arbuck S, Gwyther S, Mooney M, Rubinstein L, Shankar L, Dodd L, Kaplan R, Lacombe D, Verweij J: New response evaluation criteria in solid tumours: revised RECIST guideline (version 1.1). Eur J Cancer 2009;45: 228-247.

25 Anon. Tumour response criteria. 2008. Internet Communication. http://www.ahrg. gov/clinic/ta/gist/gisttab2.htm.

26 Kaltsas GA, Papadogias D, Makras P, Grossman AB: Treatment of advanced neuroendocrine tumours with radiolabelled somatostatin analogues. Endocr Relat Cancer 2005; 12:683-699.

27 Chrisoulidou A, Kaltsas G, Ilias I, Grossman $\mathrm{AB}$ : The diagnosis and management of malignant phaeochromocytoma and paraganglioma. Endocr Relat Cancer 2007;14:569585.

28 Ahlman H: Malignant pheochromocytoma: state of the field with future projections. Ann N Y Acad Sci 2006;1073:449-464.

29 Kolby L, Bernhardt P, Johanson V, Wangberg B, Muth A, Jansson S, Forssell-Aronsson E, Nilsson O, Ahlman H: Can quantification of VMAT and SSTR expression be helpful for planning radionuclide therapy of malignant pheochromocytomas? Ann N Y Acad Sci 2006; 1073:491-497.

- 30 Rose B, Matthay KK, Price D, Huberty J, Klencke B, Norton JA, Fitzgerald PA: Highdose 131I-metaiodobenzylguanidine therapy for 12 patients with malignant pheochromocytoma. Cancer 2003;98:239-248.

31 Lawrence JK, Maher ER, Sheaves R, Grossman AB: Familial paraganglioma: a novel presentation of a case and response to therapy with radiolabelled MIBG. Hormones (Athens) 2004;3:127-131.

32 Lam MG, Lips CJ, Jager PL, Dullaart RP, Lentjes EG, van Rijk PP, de Klerk JM: Repeated [131I]metaiodobenzylguanidine therapy in two patients with malignant pheochromocytoma. J Clin Endocrinol Metab 2005; 90:5888-5895.

33 Garaventa A, Gambini C, Villavecchia G, Di Cataldo A, Bertolazzi L, Pizzitola MR, De Bernardi B, Haupt R: Second malignancies in children with neuroblastoma after combined treatment with 131I-metaiodobenzylguanidine. Cancer 2003;97:13321338.

34 Reubi JC, Schar JC, Waser B, Wenger S, Heppeler A, Schmitt JS, Macke HR: Affinity profiles for human somatostatin receptor subtypes SST1-SST5 of somatostatin radiotracers selected for scintigraphic and radiotherapeutic use. Eur J Nucl Med 2000;27: 273-282.

35 van Essen M, Krenning EP, de Jong M, Valkema R, Kwekkeboom DJ: Peptide receptor radionuclide therapy with radiolabelled somatostatin analogues in patients with somatostatin receptor positive tumours. Acta Oncol 2007;46:723-734.

36 Arnold R, Wied M, Behr TH: Somatostatin analogues in the treatment of endocrine tumors of the gastrointestinal tract. Expert Opin Pharmacother 2002;3:643-656.

37 Oberg K: Management of neuroendocrine tumours. Ann Oncol 2004;15(suppl 4): iv293-iv298.

38 Modlin IM, Oberg K, Chung DC, Jensen RT, de Herder WW, Thakker RV, Caplin M, Delle FG, Kaltsas GA, Krenning EP, Moss SF, Nilsson O, Rindi G, Salazar R, Ruszniewski $\mathrm{P}$, Sundin A: Gastroenteropancreatic neuroendocrine tumours. Lancet Oncol 2008;9: 61-72.

39 Rohrer L, Raulf F, Bruns C, Buettner R, Hofstaedter F, Schule R: Cloning and characterization of a fourth human somatostatin receptor. Proc Natl Acad Sci USA 1993;90: 4196-4200.

40 Panetta R, Greenwood MT, Warszynska A, Demchyshyn LL, Day R, Niznik HB, Srikant $\mathrm{CB}$, Patel YC: Molecular cloning, functional characterization, and chromosomal localization of a human somatostatin receptor (somatostatin receptor type 5) with preferential affinity for somatostatin-28. Mol Pharmacol 1994;45:417-427.

41 Patel YC, Greenwood M, Panetta R, Hukovic N, Grigorakis S, Robertson LA, Srikant CB: Molecular biology of somatostatin receptor subtypes. Metabolism 1996;45:31-38. 
-42 Hofland LJ, Lamberts SW, van Hagen PM, Reubi JC, Schaeffer J, Waaijers M, van Koetsveld PM, Srinivasan A, Krenning EP, Breeman WA: Crucial role for somatostatin receptor subtype 2 in determining the uptake of [111In-DTPA-D-Phel] octreotide in somatostatin receptor-positive organs. J Nucl Med 2003;44:1315-1321.

43 John M, Meyerhof W, Richter D, Waser B, Schaer JC, Scherubl H, Boese-Landgraf J, Neuhaus P, Ziske C, Molling K, Riecken EO, Reubi JC, Wiedenmann B: Positive somatostatin receptor scintigraphy correlates with the presence of somatostatin receptor subtype 2 . Gut 1996;38:33-39.

-44 de Herder WW, Hofland LJ, van der Lely AJ, Lamberts SW: Somatostatin receptors in gastroentero-pancreatic neuroendocrine tumours. Endocr Relat Cancer 2003;10:451458.

-45 Teunissen JJ, Kwekkeboom DJ, de Jong M, Esser JP, Valkema R, Krenning EP: Endocrine tumours of the gastrointestinal tract. Peptide receptor radionuclide therapy. Best Pract Res Clin Gastroenterol 2005; 19:595616.

46 Reubi JC: Somatostatin and other peptide receptors as tools for tumor diagnosis and treatment. Neuroendocrinology 2004; 80(suppl 1):51-56.

-47 Anthony LB, Woltering EA, Espenan GD, Cronin MD, Maloney TJ, McCarthy KE: Indium-111-pentetreotide prolongs survival in gastroenteropancreatic malignancies. Semin Nucl Med 2002;32:123-132.

48 Buscombe JR, Caplin ME, Hilson AJ: Longterm efficacy of high-activity 111in-pentetreotide therapy in patients with disseminated neuroendocrine tumors. J Nucl Med 2003; 44:1-6.

-49 Otte A, Herrmann R, Heppeler A, Behe M, Jermann E, Powell P, Maecke HR, Muller J: Yttrium-90 DOTATOC: first clinical results. Eur J Nucl Med 1999;26:1439-1447.

-50 Waldherr C, Pless M, Maecke HR, Haldemann A, Mueller-Brand J: The clinical value of [90Y-DOTA]-D-Phe1-Tyr3-octreotide (90Y-DOTATOC) in the treatment of neuroendocrine tumours: a clinical phase II study. Ann Oncol 2001;12:941-945.

51 Waldherr C, Pless M, Maecke HR, Schumacher T, Crazzolara A, Nitzsche EU, Haldemann A, Mueller-Brand J: Tumor response and clinical benefit in neuroendocrine tumors after 7.4 GBq (90)Y-DOTATOC. J Nucl Med 2002;43:610-616.

-52 Paganelli G, Bodei L, Handkiewicz JD, Rocca P, Papi S, Lopera SM, Gatti M, Chinol M, Bartolomei M, Fiorenza M, Grana C: 90YDOTA-D-Phe1-Try3-octreotide in therapy of neuroendocrine malignancies. Biopolymers 2002;66:393-398.

- 53 Bushnell D, O’Dorisio T, Menda Y, Carlisle T, Zehr P, Connolly M, Karwal M, Miller S, Parker S, Bouterfa H: Evaluating the clinical effectiveness of 90Y-SMT 487 in patients with neuroendocrine tumors. J Nucl Med 2003;44:1556-1560.
Valkema R, Pauwels S, Kvols LK, Barone R, Jamar F, Bakker WH, Kwekkeboom DJ, Bouterfa H, Krenning EP: Survival and response after peptide receptor radionuclide therapy with [90Y-DOTA0,Tyr3]octreotide in patients with advanced gastroenteropancreatic neuroendocrine tumors. Semin Nucl Med 2006;36:147-156.

55 Virgolini I, Traub T, Novotny C, Leimer M, Fuger B, Li SR, Patri P, Pangerl T, Angelberger P, Raderer M, Burggasser G, Andreae F, Kurtaran A, Dudczak R: Experience with indium-111 and yttrium-90-labeled somatostatin analogs. Curr Pharm Des 2002;8: 1781-1807.

56 Leimer M, Kurtaran A, Smith-Jones P, Raderer M, Havlik E, Angelberger P, Vorbeck F, Niederle B, Herold C, Virgolini I: Response to treatment with yttrium 90-DOTA-lanreotide of a patient with metastatic gastrinoma. J Nucl Med 1998;39:2090-2094.

57 Virgolini I, Britton K, Buscombe J, Moncayo R, Paganelli G, Riva P: In- and Y-DOTA-lanreotide: results and implications of the MAURITIUS trial. Semin Nucl Med 2002; 32:148-155.

-58 van Essen M, Krenning EP, Bakker WH, de Herder WW, van Aken MO, Kwekkeboom DJ: Peptide receptor radionuclide therapy with $177 \mathrm{Lu}$-octreotate in patients with foregut carcinoid tumours of bronchial, gastric and thymic origin. Eur J Nucl Med Mol Imaging 2007;34:1219-1227.

59 van Essen M, Krenning EP, Kooij PP, Bakker WH, Feelders RA, de Herder WW, Wolbers JG, Kwekkeboom DJ: Effects of therapy with [177Lu-DOTA0, Tyr3]octreotate in patients with paraganglioma, meningioma, small cell lung carcinoma, and melanoma. J Nucl Med 2006;47:1599-1606.

60 Kwekkeboom DJ, de Herder WW, Kam BL, van Eijck CH, van Essen M, Kooij PP, Feelders RA, van Aken MO, Krenning EP: Treatment with the radiolabeled somatostatin analog [177 Lu-DOTA 0,Tyr3]octreotate: toxicity, efficacy, and survival. J Clin Oncol 2008;26: 2124-2130.

61 Pauwels S, Barone R, Walrand S, BorsonChazot F, Valkema R, Kvols LK, Krenning EP, Jamar F: Practical dosimetry of peptide receptor radionuclide therapy with $(90) \mathrm{Y}$ labeled somatostatin analogs. J Nucl Med 2005;46(suppl 1):92S-98S.

62 Kwekkeboom DJ, Teunissen JJ, Kam BL, Valkema R, de Herder WW, Krenning EP: Treatment of patients who have endocrine gastroenteropancreatic tumors with radiolabeled somatostatin analogues. Hematol Oncol Clin North Am 2007;21:561-573.
63 de Keizer B, van Aken MO, Feelders RA, de Herder WW, Kam BL, van Essen M, Krenning EP, Kwekkeboom DJ: Hormonal crises following receptor radionuclide therapy with the radiolabeled somatostatin analogue [(177)Lu-DOTA (0),Tyr (3)]octreotate. Eur J Nucl Med Mol Imaging 2008;35:749-755.

64 Valkema R, de Jong M, Bakker WH, Breeman WA, Kooij PP, Lugtenburg PJ, De Jong FH, Christiansen A, Kam BL, de Herder WW, Stridsberg M, Lindemans J, Ensing G, Krenning EP: Phase I study of peptide receptor radionuclide therapy with [InDTPA]octreotide: the Rotterdam experience. Semin Nucl Med 2002;32:110-122.

65 Otte A, Weiner SM, Cybulla M: Is radiation nephropathy caused by yttrium- 90 ? Lancet 2002;359:979.

66 Valkema R, Pauwels SA, Kvols LK, Kwekkeboom DJ, Jamar F, de Jong M, Barone R, Walrand S, Kooij PP, Bakker WH, Lasher J, Krenning EP: Long-term follow-up of renal function after peptide receptor radiation therapy with (90)Y-DOTA(0),Tyr(3)-octreotide and (177)Lu-DOTA(0), Tyr(3)-octreotate. J Nucl Med 2005;46(suppl 1):83S-91S.

-67 de Jong M, Breeman WA, Valkema R, Bernard BF, Krenning EP: Combination radionuclide therapy using $177 \mathrm{Lu}-$ and $90 \mathrm{Y}-\mathrm{la}-$ beled somatostatin analogs. J Nucl Med 2005;46(suppl 1):13S-17S.

68 O’Donoghue JA, Bardies M, Wheldon TE: Relationships between tumor size and curability for uniformly targeted therapy with beta-emitting radionuclides. J Nucl Med 1995;36:1902-1909.

69 Kunikowska J, Mikolajczak R, Pawlak D, Hubalewska-Dydejczyk A, Sowa-Staszczak A, Kobylecka M: Clinical results of PPRT with ${ }^{90} \mathrm{Y}$-DOTATATE and ${ }^{90} \mathrm{Y} /{ }^{177} \mathrm{Lu}-$ DOTATATE - What is better for therapy (abstract C61. 6th Ann ENETS Conf, March 2009, Granada).

70 Chatal JF, Le Bodic MF, Kraeber-Bodere F, Rousseau C, Resche I: Nuclear medicine applications for neuroendocrine tumors. World J Surg 2000;24:1285-1289.

71 Kaltsas G, Rockall A, Papadogias D, Reznek $\mathrm{R}$, Grossman AB: Recent advances in radiological and radionuclide imaging and therapy of neuroendocrine tumours. Eur J Endocrinol 2004;151:15-27.

72 Smith-Jones PM, Bischof C, Leimer M, Gludovacz D, Angelberger P, Pangerl T, PeckRadosavljevic M, Hamilton G, Kaserer K, Kofler A, Schlangbauer-Wadl H, Traub T, Virgolini I: DOTA-lanreotide: a novel somatostatin analog for tumor diagnosis and therapy. Endocrinology 1999; 140:51365148.

73 Wild D, Schmitt JS, Ginj M, Macke HR, Bernard $\mathrm{BF}$, Krenning $\mathrm{E}$, de Jong $\mathrm{M}$, Wenger $\mathrm{S}$, Reubi JC: DOTA-NOC, a high-affinity ligand of somatostatin receptor subtypes 2,3 and 5 for labelling with various radiometals. Eur J Nucl Med Mol Imaging 2003;30:13381347. 